Vol 10, Issue 12, 2017

Online - 2455-3891
Print - 0974-2441

$\underline{\text { Research Article }}$

\title{
EVALUATION OF RESPONSE TO ANTIHYPERTENSIVE'S IN PREECLAMPSIA AND GESTATIONAL HYPERTENSION CASES WITH DIFFERENT ACE GENE INSERTION/DELETION GENOTYPES
}

\author{
ARSHIYA AFREEN ${ }^{1 *}$, FATMA ALI ${ }^{1}$, JUHI AZIZ ${ }^{1}$, NIDA MAKEEN ${ }^{1}$, NUSRATH FATHIMA ${ }^{2}$, PADMAJA P ${ }^{3}$, \\ MOHD MOHIUDDIN ${ }^{1}$, MOHD ISHAQ ${ }^{2,4}$
}

${ }^{1}$ Department of Pharmacy, Deccan School of Pharmacy, PHARM-D (Doctor of Pharmacy), Deccan College of Medical Sciences, Hyderabad, Telangana, India. ${ }^{2}$ Department of Genetics, Osmania University, Hyderabad, Telangana, India. ${ }^{3}$ Department of Obstetrics \& Gynaecology, Princess Esra Hospital, Hyderabad, Telangana, India. ${ }^{4}$ Centre for Cellular and Molecular Medicine, Salar-E-Millat Research Centre, Princess Esra Hospital PEH, DCMS, Hyderabad, Telangana, India. Email: arshiyaafreen34@gmail.com/ishaq_50@redifmmail.com

Received: 21 June 2017, Revised and Accepted: 30 August 2017

ABSTRACT

Objective: The objective of this research study was to investigate if there exists a relationship between angiotensin converting enzyme (ACE) genes insertion/deletion (I/D) genotypes and the antihypertensive treatment being received by preeclampsia (PE) and gestational hypertension (GH) patients.

Methods: A total of $50 \mathrm{PE}$ and $35 \mathrm{GH}$ cases were included. ACE gene I/D genotyping was carried out on the blood samples of cases and correlated with the antihypertensive treatment being received by these patients. Details of antihypertensives being received by them were nifedipine (a calcium channel blocker $10 \mathrm{mg}$ ) and methyldopa (an alpha 2 receptor agonist $250 \mathrm{mg}$ ) which is considered as the first-line of treatment. 30 normotensive pregnant women of comparable gestational period served as controls.

Results: It was observed that a combination of calcium channel blocker (nifedipine $10 \mathrm{mg}$ ), as well as alpha 2 agonist (methyldopa 250 mg), was required in patients with D' allele containing genotypes. However, PE and GH patients with II genotype as well as those of GH patients responded well to either nifedipine or methyldopa. If confirmed these results appear to be of clinical significance as prior knowledge of ACE I/D genotypes will be useful in the management of PE cases in general and severe PE cases in particular.

Conclusion: Prior knowledge of ACE I/D genotypes appears to be helpful in the management of PE and GH cases.

Keywords: Preeclampsia, Gestational hypertension, Response to antihypertensive’s, Angiotensin converting enzyme insertion/deletion genotypes.

(C) 2017 The Authors. Published by Innovare Academic Sciences Pvt Ltd. This is an open access article under the CC BY license (http://creativecommons. org/licenses/by/4. 0/) DOI: http://dx.doi.org/10.22159/ajpcr.2017.v10i12.20868

\section{INTRODUCTION}

Preeclampsia (PE), a pregnancy-specific disorder is considered as a major cause of maternal and perinatal morbidity and mortality $[1,2]$. It is characterized by the presence of placental hypoxia/ischemia, excessive oxidative stress, hypertension and proteinuria in association with endothelial dysfunction after the $20^{\text {th }}$ week of gestation. PE complicates about $3 \%$ of pregnancies and increase in its incidence is attributed to changes in maternal characteristics such as maternal age and pre-pregnancy body weight as well as certain genetic factors. Poor placental perfusion is regarded as the cause for the increase in blood pressure in PE. Closely monitored antihypertensive therapy not only allows maintenance of gestation but is also likely to facilitate an increase in the gestational age of delivery thereby decreasing adverse fetal and maternal outcomes [3-5]. Thus, various maternal predisposing factors include advanced age obesity, primipara, and previous history of PE [6]. PE is essentially a multi-factorial condition, resulting due to the interaction of genetic and environmental factors. While precise pathophysiology underlying the condition is not known, but it is believed that it results due to excessive oxidative stress, and endothelial dysfunction. Renin-Angiotensin-Aldosterone System has also been implicated in the pathophysiology of $\mathrm{PE}$ as angiotensin-converting enzyme (ACE) enzyme converts inactive Angiotensin I into Angiotensin II a vasoconstrictor, an important factor contributing to hypertension and oxidative stress [7].

The objective of the present study was to determine ACE I/D genotypes in $\mathrm{PE}$ and gestational hypertension (GH) patients. The second aspect of the study was to record the details of antihypertensive treatment these patients were receiving with the ultimate objective of analyzing weather a pattern emerges showing a relationship of ACE I/D genotypes and response to antihypertensive treatment. Such studies are likely to help us to investigate the prospects of genotype based response evaluation, a step toward personalized treatment. We are unaware of such studies correlating ACE gene I/D polymorphism with response to antihypertensive in PE as well as GH patients. The choice of ACE gene was based on the reports claiming an association of $\mathrm{D}$ allele with a predisposition to PE and the protective role of "II" homozygote [8-10]. In a similar study, a single nucleotide polymorphism in endothelial nitric oxide synthase coding gene affecting the nitric oxide (NO) production was correlated with antihypertensive treatment in PE and GH [11].

The I/D polymorphism of ACE gene has been particularly evaluated as the three ID genotypes differ significantly with regard to serum concentration of Angiotensin II which is not only a vasoconstrictor but also a potent inducer of nicotinamide adenine dinucleotide phosphate (NADPH) oxidase an enzyme involved in the generation of oxygen free radicals [12]. To our knowledge, there are no earlier reports in literature evaluating response to antihypertensive treatment in PE patients with different ACE I/D genotypes.

\section{METHODS}

Selection of cases

Clinically confirmed cases of PE and GH were selected. A total of 50 PE cases and 35 GH cases were included from inpatient Gynaecology ward of Princess Esra Hospital, (Hyderabad). The study protocol was approved by Institutional Review Board of Deccan College of Medical 
Sciences, Hyderabad. Before blood collection, an informed consent form was taken from all the patients who participated in this study. Demographic details of the patients, as well as their baseline clinical characteristics, were recorded in a pro forma. The important details recorded were systolic blood pressure (SBP), diastolic blood pressure (DBP) of the patients along with the laboratory findings including proteinuria. Details of parity and the antihypertensive treatment being received by the patients were also recorded. 30 normotensive pregnant women as controls were also included in the study.

For ACE I/D genotyping, $2 \mathrm{ml}$ of intravenous blood was drawn aseptically in EDTA vacutainers and stored at $-20^{\circ} \mathrm{C}$ until further use. Genomic DNA was extracted from the blood samples according to rapid salting out method as described by Lahiri et al. (1991) [13]. Polymerase chain reaction (PCR) amplification was performed in a $25 \mu \mathrm{l}$ reaction mixture that contained $1 \mu \mathrm{g}$ of genomic DNA, $20 \mathrm{pmol}$ of each primer and $12.5 \mu \mathrm{l}$ of Taq DNA master mix (2X Takara. Japan). The forward (F) 5'-CTGGAGACCACTCCATCCTTTCT-3' and reverse (R) $5^{\prime}$-GATGTGGCCATCACATTGTCAGAT-3' primers specific to ACE I/D genotypes were used to carry out the PCR.

PCR was performed in a thermal cycler (Bio-Rad, USA) according to the method described by Seckin et al. [14]. The thermal programming was as follows; an initial denaturation step of 5 minutes at $94^{\circ} \mathrm{C}$, followed by 30 cycles of denaturation at $94^{\circ} \mathrm{C}$ for 1 minutes, annealing at $58^{\circ} \mathrm{C}$ for 1 minutes and extension at $72^{\circ} \mathrm{C}$ for 2 minutes and a final extension for 15 minutes at $72^{\circ} \mathrm{C}$. PCR products were separated by electrophoresis on $3 \%$ agarose gel. Amplified DNA fragments were then visualized under ultraviolet light in a Gel Documentation System (Bio-Rad, USA). The PCR fragments corresponding to three genotypes were $490 \mathrm{bp}$ band (II), $190 \mathrm{bp}$ (DD), and both 490 and $190 \mathrm{bp}$ (ID).

\section{Statistical analysis}

All statistical analysis was performed using SPSS software (version15). Genotypic and allelic frequencies for the three ACE I/D genotypes were calculated, and deviation from Hardy-Weinberg law was determined by both test and controls. Odds ratio was calculated by Pearson Chi-square or Fisher's exact test for determining risk or protection as appropriate. Mean and standard deviation were calculated for continuous traits such as age, pulse rate, SBP, and DBP.

\section{RESULTS}

Details of basic and clinical characteristics and mean age of the patients are provided in Table 1. Figures in parenthesis indicate a number of cases at the stage of hypertension (according to JNC-7). The mean ages in these study groups did not differ significantly. The mean SBP and
DBP in PE and GH groups before and after treatment are also provided along with that observed in normotensive. The percentage of primipara cases was $48 \%$, and that of multigravida was $52 \%$.

Table 2 summarizes the details of genotypic and allelic frequencies of ACE gene I/D polymorphism in the three study groups. In PE patients, II and ID genotypes were $12(24 \%)$ and $33(66 \%)$ respectively, $(\mathrm{p}<0.05)$ only 5 patients $(10 \%)$ with DD genotype were recorded. The "I" and " $\mathrm{D}$ " allele frequencies in PE patients were $57 \%$ and $43 \%(\mathrm{p}<0.05)$, respectively. In contrast to this, in normotensive pregnant women, the percentage of II genotype was $53 \%$, while $40 \%$ had ID genotype. Only $6.6 \%$ were with DD genotype. The frequencies of II and DD genotypes were $42.80 \%$ and $51.00 \%$, respectively, and only $5.50 \%$ were DD cases in GH. Deviation from Hardy-Weinberg equilibrium was observed between PE and control allelic and genotypic frequencies $(\mathrm{p}<0.05)$ while no such deviation was recorded in GH. The genotypic and allelic frequencies in cases of $\mathrm{GH}$ did not differ significantly from those observed in normotensive controls (Table 3).

Odds ratio analysis comparing the clinical and control groups revealed that women with ID genotype have more than three-fold increased risk (3.66) of developing PE compared with II genotype, i.e., $(\mathrm{OR}=3.66$, $\mathrm{CI}=1.35-9.95)(\mathrm{p}<0.009)$. In contrast to this women with II genotype when compared with ID genotype have a reduced risk $(\mathrm{OR}=0.27$, $\mathrm{CI}=0.10-0.74)(\mathrm{p}<0.009)$. Odds ratio analysis in "II" women with those having " $\mathrm{D}$ " allele containing genotypes (ID, DD) showed a protective effect of "I" allele $(\mathrm{OR}=0.46, \mathrm{CI}=0.25-0.84)(\mathrm{p}<0.008)$. A similar analysis for $\mathrm{GH}$ did not reveal any significant results presumably because of more or less similar genotypic frequencies in $\mathrm{GH}$ and control groups. The allele specific analysis of odds ratio revealed that " $D$ " allele carrying women may have two-fold increased the risk of developing PE.

Details of the drug response of PE and GH patients in relation to genotype are given in Table 4. It was observed that PE patients with "II" homozygous genotype responded well as assessed by BP control to nifedipine alone. In most of these patients, gestation period extended up to 36 weeks and the pregnancy outcomes were good for both mothers and the newborn.

In case of patients with " $\mathrm{D}$ " allele containing genotypes, nifedipine in combination with methyldopa was required for controlling their SBP and DBP. The reason for this could be high BP levels as a consequence of significantly higher serum and tissue concentrations of angiotensin II. Out of 33 "ID" genotype cases with PE, 30 (91) required combination therapy, i.e., nifedipine $10 \mathrm{mg}+$ methyldopa $250 \mathrm{mg}$. All the DD homozygote belonging to PE group required combination therapy. It may be noted that the presence of " $\mathrm{D}$ " allele in single and double dose

Table 1: Correlation between ACE gene I/D genotypes and antihypertensive treatment

\begin{tabular}{|c|c|c|c|c|c|c|}
\hline \multirow[t]{2}{*}{ Clinical category } & \multirow{2}{*}{$\begin{array}{l}\text { Stage of } \\
\text { hypertension (jnc-7)* }\end{array}$} & \multirow[t]{2}{*}{ Mean age (years) } & \multirow{2}{*}{$\begin{array}{l}\text { Mean } \pm \text { SD bp (before } \\
\text { treatment) }\end{array}$} & \multirow{2}{*}{$\begin{array}{l}\text { Mean bp (after } \\
\text { treatment) }\end{array}$} & \multicolumn{2}{|l|}{ Parity } \\
\hline & & & & & Primi & Multiple \\
\hline \multirow[t]{2}{*}{ PE } & $1(37)$ & $24 \pm 3.81$ & $151 \pm 7.0 / 95 \pm 4.83$ & $133 \pm 5.0 / 90 \pm 0$ & 20 & 30 \\
\hline & $2(13)$ & & $172 \pm 11.06 / 109 \pm 6.43$ & $137 \pm 1.66 / 90 \pm 0$ & & \\
\hline Gestational hypertension & $\begin{array}{l}1(27) \\
2(8)\end{array}$ & $24 \pm 3.18$ & $163 \pm 3.3 / 99 \pm 1.57$ & $130 \pm 3.3 / 90 \pm 0$ & & \\
\hline Normotensive & - & $25 \pm 3.62$ & $113 \pm 0 / 76.6 \pm 0$ & - & 12 & 18 \\
\hline
\end{tabular}

*JNC-7 indicates the Seventh Report of the Joint National Committee on Prevention, Detection Evaluation and Treatment of High Blood Pressure [15]

Table 2: Distribution of genotypic and allelic frequencies in the three study groups

\begin{tabular}{llllllll}
\hline Clinical category & \multirow{2}{*}{ Total cases } & \multicolumn{2}{l}{ ACE I/D genotypes } & & \multicolumn{2}{c}{ Allelic frequencies } \\
& & II & ID & DD & & "I" allele & “D” allele \\
\hline PE & 50 & $12(24)$ & $33^{*}(66)$ & $5(10)$ & 57.00 & $43.00^{*}$ \\
GH & 35 & $15(42.85)$ & $18(51.42)$ & $2(5.71)$ & 38.50 & 31.50 \\
Normotensive pregnant women & 30 & $16(53.3)$ & $12(40)$ & $2(6.6)$ & 73.50 & 26.50 \\
\hline
\end{tabular}




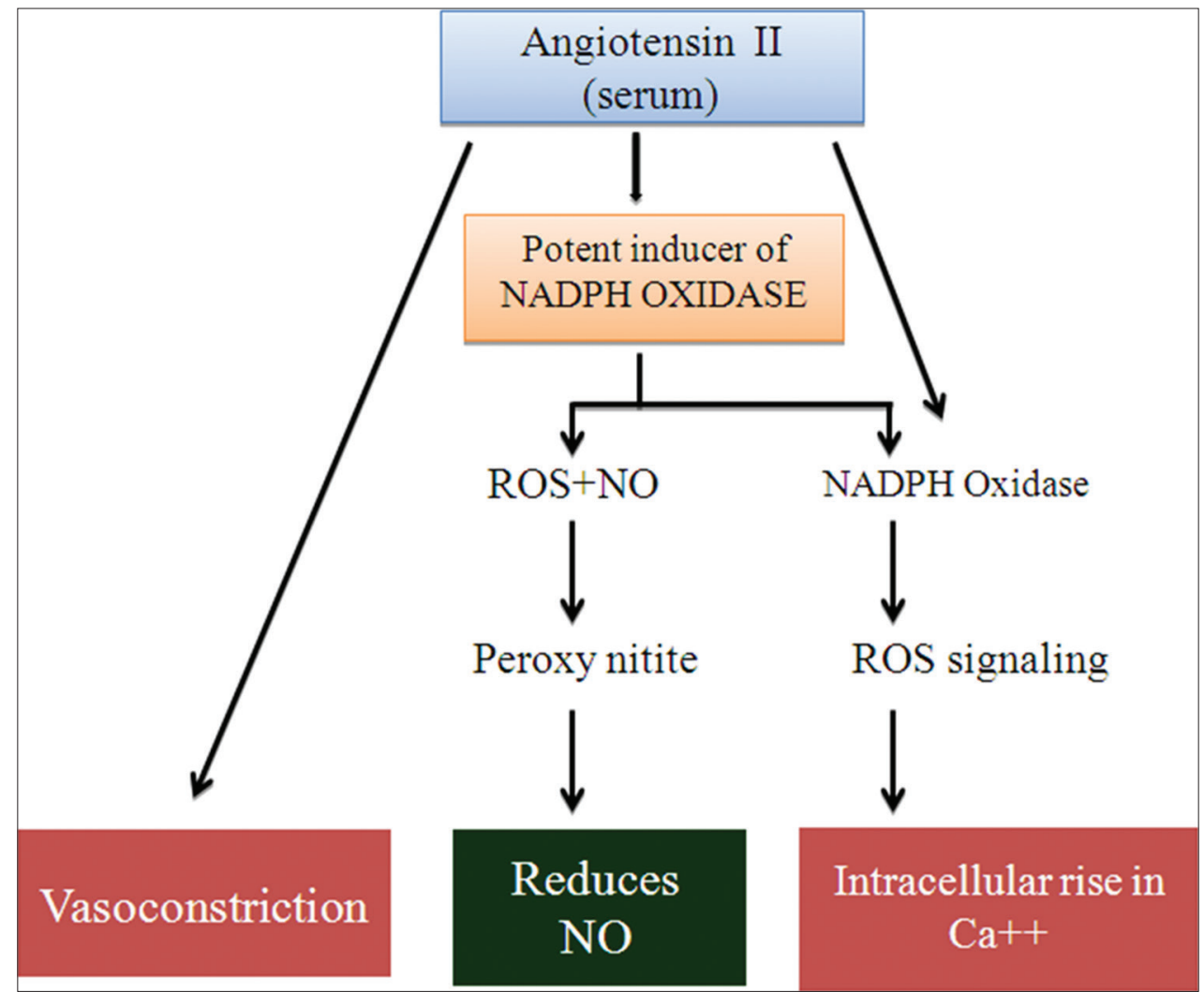

Fig. 1: Three mechanisms by which Angiotensin II induce oxidative stress and hypertension

Table 3: Odds ratio analysis for the risk/protection likely to be conferred by genotypes/alleles

\begin{tabular}{llll}
\hline Genotypes compared & $\begin{array}{l}\text { odds } \\
\text { ratio }\end{array}$ & $\begin{array}{l}\text { Confidence } \\
\text { interval (95\%) }\end{array}$ & p value \\
\hline PE-ID versus II & 3.66 & $1.35-9.99$ & $<0.009$ \\
PE-II versus ID & 0.27 & $0.10-0.74$ & $<0.009$ \\
PE-“I" allele versus “D” allele & 0.465 & $0.25-0.84$ & $<0.008$ \\
PE-“D” allele versus "I" allele & 2.112 & $1.65-3.85$ & $<0.01$ \\
GH-ID versus II & 1.6 & $0.58-4.41$ & $<0.25$ \\
GH-II versus ID & 0.625 & $0.22-1.72$ & $<0.257$ \\
GH-"I" allele versus "D” allele & 0.782 & $0.44-1.44$ & $<0.265$ \\
\hline
\end{tabular}

(DD homozygote) appears to contribute to the severity of disease and hence combination therapy (Fig. 1)

\section{DISCUSSION}

Recent developments in the field of pharmacogenomics offer prospects of individualized patient treatment there by facilitating early introduction of optimal treatment at the same time minimizing the use of inappropriate drugs. Such a strategy is likely to reduce the risk of harmful side effects to both mother and baby in clinical conditions such as PE and GH [16].

ACE gene I/D polymorphism is carried out in view of considerable reports claiming susceptibility of DD genotype and protective effects of II genotype to $\mathrm{PE}$ and $\mathrm{GH}$. In previous reports, ACE genotype has been correlated with response to ACE-inhibitors and ACE receptors Blockers (ARBs) in diabetic nephropathy cases [17].

However, ACE-inhibitors and ARBs are contraindicated in PE and GH groups. Moreover, it is well documented that the serum concentrations of Angiotensin II are significantly higher in women's with DD as well as in ID genotypes compared to those with II genotype.
It is well-known that Angiotensin II is not only a vasoconstrictor but also a potent inducer of NADPH oxidase an enzyme involved in the generation of free radicals of oxygen [18]. It is known that reactive oxygen species (ROS) interact with $\mathrm{NO}$ and converts it into peroxynitrite thereby reducing the bioavailability of $\mathrm{NO}$, a vasodilator. Moreover, intracellular row signaling results in an intracellular rise in calcium ions $\left(\mathrm{Ca}^{+2}\right)$ contributing to vasoconstriction and resulting in a rise in blood pressure. ROS increase intracellular free calcium ion concentration, a major determinant of vascular reactivity [19-22]. It is presumed that the basal rates of ROS. Production is high in DD and ID genotypes; therefore, PE patients with DD and ID genotypes may require not only nifedipine but also methyldopa, while in II homozygote's, nifedipine alone appeared to be adequate to control the blood pressure and extend the gestational period for a better pregnancy outcome.

\section{CONCLUSION}

It is inferred that Angiotensin II in view of its pleiotropic effects plays a key role in the pathophysiology of PE and GH. This may explain the differential response of PE patients with different ACE genotypes to nifedipine and combination therapy. In patients with II genotype, serum Angiotensin II is significantly less in concentration and accordingly the release of ROS by induction through NADPH oxidase may also be relatively low than that in patients with II and ID genotypes. Lack of association of ACE I/D genotypes with GH may be explained on the basis that GH is a relatively milder condition than PE both in terms of hypertension and absence of proteinuria. Oxidative stress is relatively less in GH than in PE because of less production of ROS [23]. In a similar study T2DM, +HTN cases on antihypertensives in also authors suggested combination therapy to be effective in selected patients. However, they did not carry out ACE I/D genotyping in their patients [24]. Moreover, combination therapy is required only in 7(6 ID and 1 DD) out of $35 \mathrm{GH}$ cases. Rest of the cases could be managed with either nifedipine or methyldopa. 
Table 4: Demographic and baseline clinical characteristics of PE and GH patients and controls

\begin{tabular}{|c|c|c|c|c|c|}
\hline \multirow{2}{*}{$\begin{array}{l}\text { Clinical } \\
\text { category }\end{array}$} & \multirow[t]{2}{*}{ Genotype } & \multirow{2}{*}{$\begin{array}{l}\text { Number of } \\
\text { patients }\end{array}$} & \multicolumn{3}{|c|}{ Response to antihypertensive drugs } \\
\hline & & & Nifedipine (10 mg b i d) & $\begin{array}{l}\text { Nifedipine ( } 10 \mathrm{mg} \text { b i d) + methyldopa } \\
(250 \mathrm{mg} \text { b i d) }\end{array}$ & Methyldopa (250 mg b i d) \\
\hline \multirow[t]{3}{*}{$\mathrm{PE}$} & DD & 05 & - & $5(100)$ & - \\
\hline & ID & 33 & 03 (09) & $30(91)$ & - \\
\hline & II & 12 & $12(100)$ & - & - \\
\hline Gestational & DD & 2 & $1(50)$ & $1(50)$ & - \\
\hline hypertensio & ID & 18 & $9(50)$ & $6(33.33)$ & $3(16.66)$ \\
\hline $\mathrm{N}$ & II & 15 & $10(66.66)$ & - & $5(33.33)$ \\
\hline
\end{tabular}

\section{REFERENCES}

1. Why Mothers Die: Report on Confidential Enquiries Into Maternal Deaths in the United Kingdom 1997-1999. London: Royal College of Obstetricians and Gynecologists; 2001

2. Hutcheon JA, Lisonkova S, Joseph KS. Epidemiology of pre-eclampsia and the other hypertensive disorders of pregnancy. Best Pract Res Clin Obstet Gynaecol 2011;25(4):391-403.

3. Venkateshwaramurthy N, John C, Perumal P. Study on anti-hypertensive in preeclampsia. Asian J Pharm Clin Res 2012;5(3):0974-2441.

4. Velusamy S. Comparision of treatment outcome of antihypertensive drugs in the management of pregnancy induced hypertension. Int $\mathrm{J}$ Pharm Pharm Sci 2017; 9(3):287-9.

5. Jhansi C, Mys H, Sandeep K, Rao PC, Lakshmi CC. Comparison of efficiency and safety of oral labetalol and nifedipine in preeclampsia: A prospective observational study. Int $\mathrm{J}$ Pharm Pharm Sci 2015;7(9):277-80.

6. Salimi S, Mokhtari M, Yaghmaei M, Jamshidi M, Naghavi A. Association of angiotensin-converting enzyme intron 16 insertion/ deletion and angiotensin II Type 1 receptor A1166C gene polymorphisms with preeclampsia in South East of Iran. J Biomed Biotechnol 2011;2011:941515.

7. Aggarwal S, Dimri N, Tandon I, Agarwal S. Preeclampsia in North Indian women: The contribution of genetic polymorphisms. J Obstet Gynaecol Res 2011;37(10):1335-41.

8. Rahimi Z, Rahimi Z, Mozafari H, Parsian A. Preeclampsia and angiotensin converting enzyme(ACE) I/D and angiotensin II Type 1 receptor (ATIR) A1166C polymorphisms: Association with ACE I/D polymorphism. J Renin Angiotens Aldosterone Syst0 2012;14(2):174-80.

9. Bereketoglu C, Kasap M, Pazarbasi A. Studies on angiotensin converting enzyme insertion/deletion polymorphism and genotype distributions in Turkish population. J Pregn 2012;108206:4.

10. Sandrim VC, Palei AC, Luizon MR, Izidoro-Toledo TC, Cavalli RC, Tanus-Santos JE. Enos haplotypes affect the responsiveness to antihypertensive therapy in preeclampsia but not in gestational hypertension. Pharmacogenomics J 2010;10(1):40-5.

11. Mello G, Parretti E, Gensini F, Sticchi E, Mecacci F, Scarselli G, et al. Maternal-fetal flow, negative events, and preeclampsia: Role of ACE I/D polymorphism. Hypertension 2003;41(4):932-7.
12. Lahiri DK, Nurnberger JI Jr. A rapid non-enzymatic method for the preparation of HMW DNA from blood for RFLP studies. Nucleic Acids Res 1991;19(19):5444.

13. Seckin D, Illhan N, Ilkey E, Illhan N, Ilkay E. ACE gene polymorphism is associated with the extent of coronary atherosclerosis. Adv Mol Med 2005;1:87-91.

14. Podymow T, August P. Update on the use of antihypertensive drugs in pregnancy. Hypertension 2008;51(4):960-9.

15. JNC 7. $7^{\text {th }}$ Report of the Joint National Committee on Prevention, detection evaluation and treatment of high blood pressure. The JNC 7 Report. J Am Med Assoc 2003;289(19):2563.

16. Williams PJ, Morgan L. The role of genetics in pre-eclampsia and potential pharmacogenomic interventions. Pharmgenomics Pers Med 2012;5:37-51.

17. Jacobsen P, Rossing K, Rossing P, Tarnow L, Mallet C, Poirier O, et al. Angiotensin converting enzyme gene polymorphism and $\mathrm{ACE}$ inhibition in diabetic nephropathy. Kidney Int 1998;53(4):1002-6.

18. Warnholtz A, Nickenig G, Schulz E, Macharzina R, Bräsen JH, Skatchkov M, et al. Increased NADH-oxidase-mediated superoxide production in the early stages of atherosclerosis: Evidence for involvement of the renin-angiotensin system. Circulation 1999;99(15):2027-33.

19. Paravicini TM, Touyz RM. Redox signaling in hypertension. Cardiovasc Res 2006;71(2):247-58.

20. Montezano AC, Nguyen Dinh Cat A, Rios FJ, Touyz RM. Angiotensin II and vascular injury. Curr Hypertens Rep 2014;16(6):431.

21. Nguyen Dinh Cat A, Montezano AC, Burger D, Touyz RM. Angiotensin II, NADPH oxidase, and redox signaling in the vasculature. Antioxid Redox Signal 2013;19(10):1110-20.

22. Imanishi T, Kobayashi K, Kuroi A, Mochizuki S, Goto M, Yoshida K, et al. Effects of angiotensin II on NO bioavailability evaluated using a catheter-type NO sensor. Hypertension 2006;48(6):1058-65.

23. Sheena PS. Comparative study of oxidative stress in pregnancy induced hypertension preeclampsia and Eclampsia. Int J Biomed Adv Res 2012;3(11):810-4.

24. Paulose RM, Bairy KL, Prabhu MM, Eesha BR, Nayak V, Tripathy A. Comparison of efficiency and adverse drug reactions of monotherapy versus combination therapy of antihypertensive among diabetic hypertensive patients in a tertiary care hospital. Asian J Pharm Clin Res 2016;10(2):0974-2441. 